\title{
TREATMENT OF WATER CONTAMINATED WITH DI-N-BUTYL PHTHALATE BY PHOTO-FENTON PROCESS
}

B.S. AL-TAWABINI

Selected from papers presented at the 7th Conference on Environmental Science and Technology,

3-6 September 2001, Ermoupolis, Syros island, Greece.
Research Institute,

King Fahd University of Petroleum \& Minerals P.0. Box \# 952, Dhahran 31261, Saudi Arabia

to whom all correspondence should be addressed:

tel : + 966-3-860-4386

fax: + 966-3-860-4029

e-mail: bassamst@kfupm.edu.sa

\section{ABSTRACT}

This study was conducted to assess the removal efficiency of Di-n-butyl phthalate (DnBP) from aqueous medium using the photo-Fenton process. The Fenton's reagent that consists of a mixture of hydrogen peroxide $\left(\mathrm{H}_{2} \mathrm{O}\right)$ and ferrous ions $\left(\mathrm{Fe}^{2+}\right)$ was used to generate the hydroxyl radical $\left(\mathrm{OH}^{0}\right)$ that attacks the target contaminant and degrade it. An ultraviolet (UV) source was used to provide the radiation needed in the photo-Fenton method (i.e. $\mathrm{UV} / \mathrm{H}_{2} \mathrm{O}_{2} / \mathrm{Fe}^{2+}$ ). The results demonstrated that photo-Fenton process was more effective and faster than Fenton's reagent in removing DnBP and that photolysis by UV irradiation was the dominant mechanism in degrading the compound. The results also showed that enhancing the removal via UV irradiation was achieved by increasing either the temperature or the $\mathrm{H}_{2} \mathrm{O}_{2}$ concentration.

KEYWORDS: Ultraviolet light, hydrogen peroxide, hydroxyl radical, phthalates, advanced oxidation processes, Fenton's reagent.

\section{INTRODUCTION}

Recent progress in chemical water treatment has lead to the development of Advanced Oxidation Processes (AOPs). These processes employ chemical, photochemical, sonochemical or radiolytic techniques to bring about chemical degradation of pollutants (Huston and Pignatello, 1999). AOPs are based on the generation of hydroxyl radical $\left(\mathrm{OH}^{0}\right)$, which has a high oxidation potential $(2.8 \mathrm{~V})$ that can sometimes completely convert the organic contaminant into $\mathrm{CO}_{2}$ and $\mathrm{H}_{2} \mathrm{O}$ (Ruppert and Bauer, 1994, Andreozzi et al., 2000).
Fenton $\left(\mathrm{H}_{2} \mathrm{O}_{2} / \mathrm{Fe}^{2+}\right)$ and photo-Fenton $\left(\mathrm{UV} / \mathrm{H}_{2} \mathrm{O}_{2} /\right.$ $\mathrm{Fe}^{2+}$ ) methods have proved to be effective and economical AOP methods used for the detoxification and degradation of many organic compounds (Lin et al., 2000). Research Studies using Fenton's reagent have demonstrated its ability to oxidize pesticides (Huston and Pignatello, 1999), phenols, (Kwon et al., 1999, Kiwi et al., 1994, Wang et al., 1999), aromatics (Casero et al., 1997, Chen et al., 1997), dyes (Li et al., 1999), surfactants (Lin et al., 1998) and polychlorinated biphenyls (PCBs) (Sedlak et al., 1991).

Fenton's reagent is a mixture of $\mathrm{H}_{2} \mathrm{O}_{2}$ and ferrous 
iron, which generate hydroxyl radicals according to the following reaction:

$$
\mathrm{Fe}^{2+}+\mathrm{H}_{2} \mathrm{O}_{2} \Rightarrow \mathrm{F}^{3+}+\mathrm{OH}^{-}+\mathrm{OH}^{0}
$$

In the presence of substrate, such as a target contaminant, the hydroxyl radicals generated are capable of detoxifying the contaminants via oxidation. Various competing reactions, which involve $\mathrm{Fe}^{2+}$, $\mathrm{Fe}^{3+}, \mathrm{H}_{2} \mathrm{O}_{2}, \mathrm{OH}^{\mathrm{o}}$ radicals, super-oxide radicals, and derived from the substrate, are also possible during Fenton's reagent treatment (Venkatadri, 1993). The catalytic effect of $\mathrm{Fe}^{2+}$ can be enhanced by irradiating the solution with ultraviolet (UV) light. The so-called photo-Fenton process increases the regeneration rate of $\mathrm{Fe}^{2+}$ and generates more species of hydroxyl radicals as shown by reaction (2). This is expected to enhance the oxidation process (Kim et. al., 1998). Thus, the photo-Fenton process can be basically represented by combining reactions (1) with reaction (2).

$$
\mathrm{Fe}^{3+}+h_{v} \Rightarrow \mathrm{Fe}^{2+}+\mathrm{OH}^{0}
$$

Di-n-butyl phthalate (DnBP) (Figure 1) was used as a model compound. This chemical is one of phthalic acid diesters and it is slightly soluble in water (11.2 mg 1-1) (Staples et al., 1997). It has low volatility and it is widely used in epoxy resins and cellulose esters and specialized adhesive formulations. It is also listed as a priority pollutant by the U. S. Environmental Protection Agency (Bauer et al., 1998). Release of DnBP into the environment can occur during manufacturing, use, and disposal

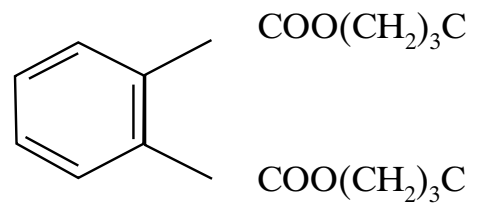

Figure 1. Di-n-Butyl Phthalate (DnBP)

where they become ubiquitous pollutants.

Some researchers studied the degradation of several phthalate esters by microorganisms under aerobic and aerobic conditions (Cartwright et. al., 2000), while others investigated the fate of phthalates by adsorption on solid medium (Hunter et al., 2000). However, little work has been done to study the degradation of phthalate esters in aqueous medium by photo-oxidation mechanism.

The main objective of this study is to evaluate the efficiency of removing DnBP from contaminated water using photo-Fenton processes.

\section{Materials \& methods}

A bench-scale batch reactor of 1.21 Pyrex-glass cylindrical vessel equipped with an outer Plexiglas cylindrical vessel used as a water jacket. A low-pressure ultraviolet (UV) lamp irradiating at a wavelength of approximately $254 \mathrm{~nm}$ with an output intensity of about $100 \mathrm{mWatt}$ was used for illumination purpose. In the Fenton's experiments, the residual DnBP concentrations were measured after 1, 2 and 3 hours, while they were measured at fractions of an hour in photo-Fenton experiments.

The DnBP standard solutions from Chemical Service, England with purities of approximately 99 $\%$ were used. Stock standard dilutions were prepared in methanol. DnBP concentrations of 0.02 $\mathrm{mM}$ (i.e. 5.6 ppm) were spiked in a distilled, deionized distilled water. This concentration was selected as half of the chemical solubility in aqueous medium according to Staples et al. (1997).

Ferrous sulfate $\left(\mathrm{FeSO}_{4} \cdot 7 \mathrm{H}_{2} \mathrm{O}\right)$ from Riedel-De Haen AG was used to prepare the ferrous solutions, which were prepared daily. Stock hydrogen peroxide $\left(\mathrm{H}_{2} \mathrm{O}_{2}\right)$ of $35 \%$ purity from Fluka AG was used to prepare the $\mathrm{H}_{2} \mathrm{O}_{2}$ solution. The $\mathrm{H}_{2} \mathrm{O}_{2}$ solution was standardized with potassium permanganate

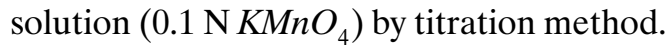

The residual DnBP concentrations were measured by a Gas Chromatograph (GC) equipped with a Photo-Ionization Detector (PID). A DB-5 fused silica capillary column of $30 \mathrm{~m}$ long and $0.53 \mathrm{~mm}$ i.d. was used for the separation purpose. The oven temperature was programmed from $80{ }^{\circ} \mathrm{C}$ to 200 ${ }^{\circ} \mathrm{C}$ at a ramp rate of $20^{\circ} \mathrm{C}$, with an initial and final hold time of 2 and 12 minutes respectively. Both detector and injector temperatures were set at $280^{\circ} \mathrm{C}$. Helium gas was used as a carrier at a flow rate of $3 \mathrm{ml}$ and a makeup of $27 \mathrm{ml}$. One (1) $\mu \mathrm{l}$ of the extract was injected into the GC by split/splitless mode. The extracts were prepared using a liquidliquid extraction (LLE) procedure. Twenty (20) $\mathrm{ml}$ water samples were extracted, by shaking for one minute, with $10 \mathrm{ml}$ mixture of methylene chloride (MDC) and n-hexane (v/v 1:3). The non-aqueous phase was then concentrated to $2 \mathrm{ml}$ by purging with nitrogen gas. This procedure was found to have a recovery of about 90 to $95 \%$. Due to the low sol- 
Table 1. Percentage of DnBP removal by Fenton's Reagent at various $\mathrm{Fe}^{2+}$ and $\mathrm{H}_{2} \mathrm{O}_{2}$ concentrations.

\begin{tabular}{|c|c|c|c|c|c|c|c|c|}
\hline $\begin{array}{c}\mathrm{DNBP}_{i} \\
(\mathrm{mM})\end{array}$ & $\begin{array}{l}\mathrm{H}_{2} \mathrm{O}_{2} \\
(\mathbf{m M})\end{array}$ & $\begin{array}{l}\mathbf{F e}(\mathrm{II}) \\
(\mathbf{m M})\end{array}$ & $\mathrm{H}_{2} \mathrm{O}_{2} / \mathrm{DNBPi}$ & $\mathrm{H}_{2} \mathrm{O}_{2} / \mathrm{Fe}$ & $\mathrm{Fe} / \mathrm{DNBPi}$ & pH & $\begin{array}{l}\text { Temp. } \\
\left({ }^{\circ} \mathrm{C}\right)\end{array}$ & $\begin{array}{c}\% \text { DNBP } \\
\text { Removed } \\
\text { after } 3 \text { hrs }\end{array}$ \\
\hline 0.02 & 0 & 0 & 0 & & & 3 & 25 & 0.0 \\
\hline 0.02 & 5 & 0 & 250 & & & 3 & 25 & 5.94 \\
\hline 0.02 & 1 & 0.1 & 50 & 10 & 5 & 3 & 25 & 22.89 \\
\hline 0.02 & 1 & 0.5 & 50 & 2 & 25 & 3 & 25 & 19.67 \\
\hline 0.02 & 1 & 1 & 50 & 1 & 50 & 3 & 25 & 29.43 \\
\hline 0.02 & 2 & 0.1 & 100 & 20 & 5 & 3 & 25 & 17.34 \\
\hline 0.02 & 2 & 0.5 & 100 & 4 & 25 & 3 & 25 & 25.35 \\
\hline 0.02 & 2 & 1 & 100 & 2 & 50 & 3 & 25 & 22.33 \\
\hline 0.02 & 5 & 0.1 & 250 & 50 & 5 & 3 & 25 & 7.77 \\
\hline 0.02 & 5 & 0.5 & 250 & 10 & 25 & 3 & 25 & 18.58 \\
\hline 0.02 & 5 & 1 & 250 & 5 & 50 & 3 & 25 & 16.67 \\
\hline 0.02 & 2 & 0.5 & 250 & 4 & 25 & 3 & 45 & 39.8 \\
\hline 0.02 & 5 & 0.5 & 250 & 10 & 25 & 3 & 45 & 40.3 \\
\hline
\end{tabular}

ubility of DnBP in water, the DnBP - contaminated water samples were stirred for along time to ensure that DnBP was dissolved in the water.

\section{RESULTS AND DISCUSSION Degradation of DnBP by Fenton's Reagent}

In this phase of the experiment, $400 \mathrm{ml}$ water samples spiked with $0.02 \mathrm{mM}$ DnBP was treated with a mixture of $\mathrm{Fe}^{2+}$ at concentrations of $0.1,0.5$ and $1.0 \mathrm{mM}$ and $\mathrm{H}_{2} \mathrm{O}_{2}$ at concentrations of 1,2 and 5 $\mathrm{mM}$. The results are listed in Table 1 . The results in this table indicate that even though $\mathrm{H}_{2} \mathrm{O}_{2}$ is considered as a powerful oxidizing agent, its efficiency in oxidizing DnBP was negligible (5.9\%). It can be concluded that DnBP was not removed by the action of $\mathrm{H}_{2} \mathrm{O}_{2}$ alone.

Similarly, when $\mathrm{H}_{2} \mathrm{O}_{2}$ was combined with $\mathrm{Fe}^{2+}$ (Fenton's reagent), only partial removal of DnBP was observed. The removal percentages in this phase under all combinations tested were below $40 \%$. This is an indicative of the slow degradation process and can be attributed to the slowness of the reaction between the $\mathrm{OH}^{\circ}$ radicals and the DnBP. Another reason can be due to the existence of the co-solvent (i.e. methanol), which was used to enhance the solubility of DnBP in water. Methanol may inhibit the reaction of the $\mathrm{OH}$ radical with the DnBP.

It is worth-mentioning here that $\mathrm{pH}$ values were kept in the range of 2.5 to 3.0 since this range is the one proved to work best for Fenton's reagent. On the other hand, to evaluate the effect of temperature on the DnBP removal efficiency by Fenton's reagent, the temperature of the contaminated water was increased from $25^{\circ} \mathrm{C}$ to $45^{\circ} \mathrm{C}$. The results showed that a slight improvement in the removal efficiency was observed at high temperatures irrespective of the initial concentration of $\mathrm{H}_{2} \mathrm{O}_{2}$ used. This indicates that the reaction in equation (1) is temperature dependent. However, the extent of removal of DnBP under these conditions is still considered low and need to be improved. Thus UV irradiation source was introduced to enhance the removal efficiency as explained earlier.

\section{Degradation of DnBP by Photo-Fenton Process}

UV light is expected to enhance the generation of $\mathrm{OH}^{\circ}$ radicals and therefore more removal of DnBP will take place as revealed by equation 2 . In this phase of the experiment, a UV lamp was used to supply the radiation. DnBP residual concentrations were measured at $0,15,30,45$ and 60 minutes. When UV irradiation source was combined with Fenton's Reagent (i.e. $2 \mathrm{mM} \mathrm{H}_{2} \mathrm{O}_{2}$ and $0.1 \mathrm{mM}$ $\mathrm{Fe}^{2+}$ ) the removal of DnBP was increased to $70 \%$ as shown in Figure 2. However, when $\mathrm{Fe}^{2+}$ concentration was increased to $0.5 \mathrm{mM}$, the removal efficiency decreased to only $43 \%$. This loss of efficiency can be due to the deposition of iron particles on the UV lamp sleeves. These particles obstruct the passage of the UV light and reduce the amount of $\mathrm{OH}$ radicals generated and thus cause a 


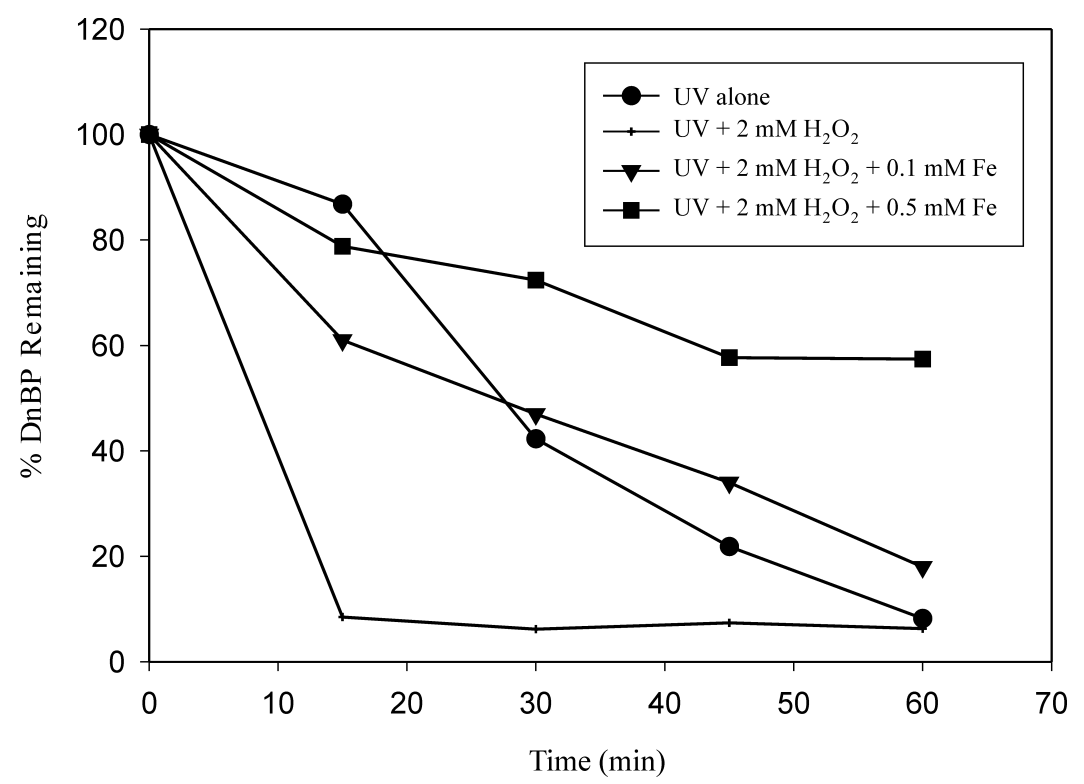

Figure 2. Removal of DnBP by Photo-Fenton Process

reduction in the removal efficiency of the DnBP. Further more, Figure 2 also shows that an exposure time of 60 minutes was needed to remove the DnBP when the sample was irradiated by a UV source alone without introducing any other chemical, while only 15 minutes was needed for the removal of the contaminant when a $2 \mathrm{mM}$ of $\mathrm{H}_{2} \mathrm{O}_{2}$, was used without $\mathrm{Fe}^{2+}$, to remove the contaminant. In this case, both actions of photolysis by UV and oxidation by $\mathrm{H}_{2} \mathrm{O}_{2}$ were combined to degrade the target compound. This clearly indicates that the removal efficiency by $\mathrm{UV} / \mathrm{H}_{2} \mathrm{O}_{2}$ is superior over Fenton and photo-Fenton process.

This result indicates that DnBP is susceptible to degradation by photolysis with UV light. This mechanism of DnBP degradation seems dominant over other degradation mechanisms.

Again, the effect of temperature was investigated in this phase. Figure 3 shows that when the UV was combined with heat source (by elevating the temperature of the contaminated water to $45^{\circ} \mathrm{C}$ ), more than $90 \%$ DnBP removal was observed without the addition of $\mathrm{H}_{2} \mathrm{O}_{2}$. In this case, the action of thermal degradation was probably combined with the action of photolysis to enhance the degradation efficiency.

\section{SUMMARY AND CONCLUSION}

In this study, the degradation of DnBP was investigated under a combination of $\mathrm{UV}, \mathrm{H}_{2} \mathrm{O}_{2}$ and $\mathrm{Fe}^{2+}$. Several proportions of $\mathrm{Fe}^{2+}$ to $\mathrm{H}_{2} \mathrm{O}_{2}$ were tested.
The $\mathrm{pH}$ was kept in the range of 2.5 to 3.0 while the temperature was set at 25 and $45^{\circ} \mathrm{C} \pm 2^{\circ} \mathrm{C}$ by a water jacket. Residual concentration of DnBP compound was taken after 1,2 , and 3 hours in the Fenton's experiments and after 15, 30, 45 and 60 minutes in the photo-Fenton process. The results of this study demonstrated that the Fenton's reagent (i.e. $\mathrm{Fe}^{2+}+\mathrm{H}_{2} \mathrm{O}_{2}$ ) system was not very effective in degrading the DnBP at the conditions used. This might be attributed the slowness of the reaction of compound with the OHo radical species or the inhibition caused by the co-solvent (methanol).

On the other hand, UV irradiation alone was found to be effective in removing 50\% DnBP in half an hour and more than $90 \%$ in one hour. Moreover, the results showed that when UV source was combined with $\mathrm{H}_{2} \mathrm{O}_{2}$ or with heat, excellent removal was achieved in less than 15 minutes. The deposition of iron particles on the UV lamp sleeves and increase turbidity of the solution reduced the intensity of radiation and hence, the removal efficiency of DnBP decreased. Finally, it can be concluded that the treatment process consists a UV source combined with $\mathrm{H}_{2} \mathrm{O}_{2}$ and or heat is better than photo-Fenton process for degrading the DnBP.

\section{ACKNOWLEDGEMENT}

The author wish to acknowledge the support of the Research Institute of King Fahd University of Petroleum and Minerals, Dhahran, Saudi Arabia. 


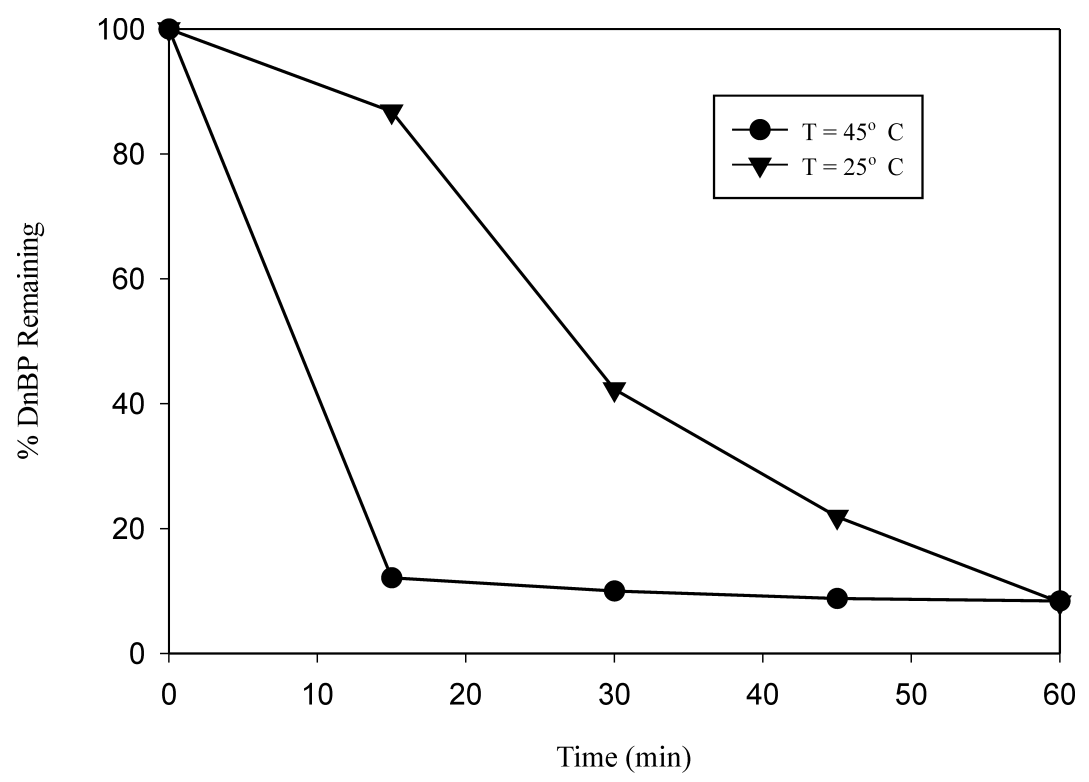

Figure 3. Effect of Temperature on The Removal of DnBP

\section{REFERENCES}

Andreozzi, R., Caprio, V., Insola, A., Marotta, R. and Sanchirico, R. (2000), Advanced Oxidation Processes For the Treatment of Mineral Oil-Contaminated Wastewaters, Water Res., 34, 620 - 628.

Bauer, M., Herrmann, R., Martin, A. and Zellmann, H. (1998), Chemodynamics, Transport Behaviour and Treatment of Phthalic Acid Esters in Municipal Landfill Leachates, Wat. Sci. Tech., 38, 185 - 192.

Bauer, R. (1994), Applicability of Solar Irradiation For Photochemical Wastewater Treatment, Chemosphere, 29, 1225-1233.

Cartwright, C., Thompson, I. And Burns, R. (2000), Degradation and Impact of Phthalate Plasticizers on Soil Microbial Communities, Environ. Toxicol. Chem., 19, 1253 - 1261.

Casero, I., Sicilia, D., Subio, S. and Perez-Bendito, D. (1997), Chemical Degradation of Aromatic Amines by Fenton's Reagent, Water Res., 31, 1985 - 1995.

Chen, R. and Pignatello, J. (1997), Role of Quinone Intermediates as Electron Shuttles in Fenton and Photoassisted Fenton Oxidations of Aromatic Compounds, Environ. Sci. Technol., 31, 2399-2406.

Hunter, J. and Christpher, G. (2000), Adsorption of Phthalate Esters on Soil at Near Saturation Conditions, J. Environ. Sci. Health, A 35, 1503-1515.

Huston, P. and Pignatello, J. (1999), Degradation of Selected Pesticide Active Ingredients and Commercial Formulations in Water by the Photo-Assisted Fenton Reactio, Water Res., 33, 1238 - 1246.

Kim, S-M and Vogelpohl, A. (1998), Degradation of Organic Pollutants by the Photo-Fenton Process, Chemical Engineering \& Technology, 21, 187-191.

Kiwi, J., Pulgarin, C. and Peringer, P. (1994), Effect of Fenton and photo-Fenton reactions on the degradation and biodegradability of 2 and 4-nitrophenols in water treatment, Applied Catalysis B: Environmental, 3, 335-350.

Kwon, B., Lee, D., Kang, N. and Yoon, J. (1999), Characteristics of P-Chlorophenol Oxidation by Fenton's Reagent, Water Res., 33, 2110 - 2118.

Li, Y-S, Liu, C-C and Fang, Y-Y. (1999), Decolorization of Dye wastewater by Hydrogen Peroxide in the Presence of Basic Oxygen Furnace Slag, J. Environ. Sci. Health, A 34, 1205-1221.

Lin, J-G. and Ma, Y-S. (2000), Oxidation of 2-Chlorophenol in Water by Ultrasound/Fenton Method, J. of Env. Eng., 126, 130 - 137.

Lin, S., Lin, C. and Leu, H. (1999), Operating Characteristics and Kinetic Studies of Surfactant Wastewater Treatment by Fenton Oxidation, Water Res., 33, 1735 - 1741.

Naddtochenko and Kiwi, J. (1998), Primary Photochemical Reactions in the Photo-Fenton System with Ferric 
Chloride. 1. A Case Study of Xylidine Oxidation as a Model Compound, Environ. Sci. Technol., 25, 1419. Ruppert, G. and Bauer, R. (1994), UV-O3, UV-H2O2, UV-TiO2 and the Photo-Fenton Reaction-Comparison of Advanced Oxidation Processes For Wastewater Treatment, Chemosphere, 28, 1447-1454.

Sedlak, D. and Andrin, A. (1991), Aqueous-Phase Oxidation of Polychlorinated Biphenyls by Hydroxyl Radicals, Environ. Sci. Technol., 25, 1419.

Staples, C., Peterson, D. Parkerton, T. and Adams W. (1997), The Environmental Fate of Phthalate Esters: A Literature Review, Chemosphere, 35, 667 - 749.

Venkatadri, R. and Peters, R. (1993), Chemical Oxidation Technologies: Ultraviolet light/Hydrogen Peroxide, Fenton's Reagent and Titanium Dioxide-Assisted Photocatalysis, Hazard. Waste Hazrd. Mater., 10, 107149 .

Wang, T-H., Kang, S-F and Lin Y-H. (1999), Comparison Among Fenton-Related Processes to Remove 2,4Dinitrophenol, J. of Env. Sci. \& Health., A34, 1267 - 1281. 